\title{
Some Considerations Upon the Actual Challenges and Opportunities for Agriculture
}

\author{
Alexandru Naghiu* \\ University of Agricultural Sciences and Veterinary Medicine, Romania
}

ISSN: 2637-7659

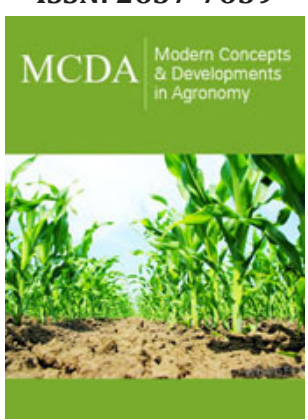

*Corresponding author: Alexandru Naghiu, University of Agricultural Sciences and Veterinary Medicine, Cluj-Napoca, Transylvania, Romania

Submission: 筒June 08, 2020

Published: 侮June 11, 2020

Volume 6 - Issue 3

How to cite this article: Alexandru Naghiu. Some Considerations Upon the Actual Challenges and Opportunities for Agriculture. Mod Concep Dev Agrono. 6(3). MCDA. 000640. 2020. DOI: 10.31031/MCDA.2020.06.000640

Copyright@ Alexandru Naghiu, This article is distributed under the terms of the Creative Commons Attribution 4.0 International License, which permits unrestricted use and redistribution provided that the original author and source are credited.

\section{Background}

Now, at the beginning of the 21st millennium, the world is going through a new and critical era, one of great challenges related to food, water, energy, healthy environment and security, in the conditions of increasing population and climate change. The Earth's population is still growing (it is true that it has reached the peak of the asymptote), according to the latest estimates, it is expected to reach 9.8 billion in 2050 and 11.2 billion in 2100 [1] and the world agricultural production has increased by $145 \%$. from 1960 [2]. In the same time, the food loss and waste has become an important issue as today represents more than $1 / 3$ of total $(1,3$ billiard of tons/year!) [3]. World food production offers a "pie" big enough to feed everybody, but its distribution (how and by whom?) at world level is a political question/decision not a technical one. Upon the results of the studies made by ECOFYS: "in 2010 crop production was enough to feed 12 billion people and the world can produce more" [4]. For 2050, all over the world, FAO expects an increase in energy consumption of $80 \%$, water consumption by $55 \%$ and food consumption by $60 \%$. Over time, humanity has passed through various stages of development arriving today at a very high level (Figure 1) and so there are created the conditions for an optimum development [5]. In this context agriculture 4.0 is the optimum response of scientists and farmers to these challenges, as a new concept that has the mission to lead the further development.

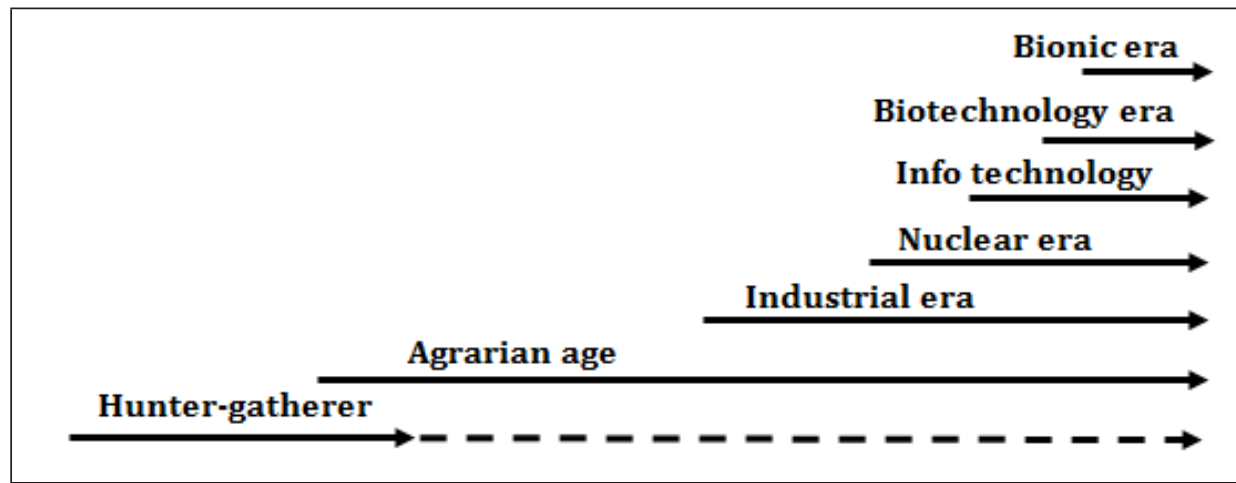

Figure 1: Humanity development stages from the beginnings till today.

\section{Approaches}

Alongside climate change and globalization, digitalization is one of the biggest challenges for us today and for future generations, for our economy and for the whole agri-food chain. Digitization has great political and economic dimension with important consequences, but also a strong consumer dimension, as well as a great impact on the farmers. It is a wideranging issue that will have a profound effect on the future of agriculture. We all know that change is taking place, but "how", "how fast" and "how deep" are the issues that have yet to be discussed and agreed. At the same time, the imperfection of the most of developed concepts \& systems must be corrected as they are too complex or inflexible to change. The actual great objective for the agri-food system is to move fast to sustainability and efficiency 
in a period of uncertainty, under the pressure of high expectations. The sustainable supply of nutrient-rich and safe foods+different by-products, while keeping natural capital in the climate change conditions, is one of the greatest challenges for the agriculture of the 21st century [6].

The optimum management of soil resources and water, intelligent plant protection and efficient energy use are becoming increasingly stringent and the amount of necessary integrate researches is high [7]. In this integrate system (Figure 2), innovative application techniques, resource-efficient procedures, electronic operating systems, drones and robotics are just some of the key issues to be discussed and implemented, together with a correct legal framework. The use of robots and drones, tractors and technological machines equipped with intelligent sensors and modern meteorological stations in the farms should increase more and more together with the processing and storage of collected dates systems. The applied informatics has a very important role in this system of precise agriculture, also. Being such a complex issue, the agriculture 4.0 issues can be resolved only by a very complex team including agricultural engineers, agri-mechanics, chemists, electronics, etc. that, perhaps, have never talked together so far. In the same time, integration in a continuous education system is very important for the farmers' success.

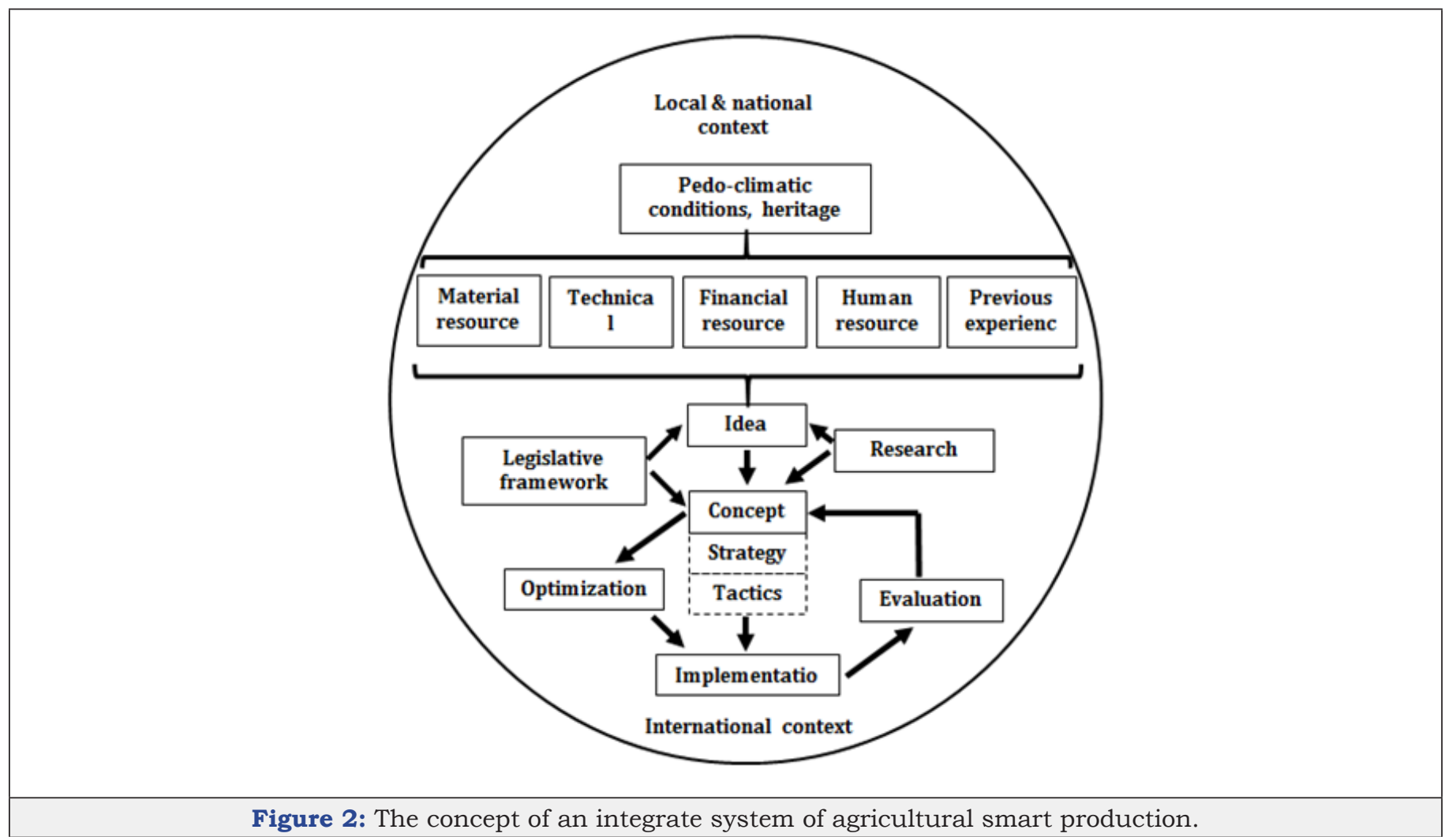

\section{Conclusion}

In short, in my opinion, the main conclusions are:

A. Besides challenges, agriculture has today, at its disposition, the necessary technology to solve all of them.

B. Farmers, scientists, politicians, multinational corporations and citizens must sit at the same table and discuss and solve all the problems and development strategies.

C. It is very important to organize the exchange of information and cooperation between science, practice and machine \& agrichemical industry.

D. Promotion of the leadership of meritocracy is a key issue.

E. The environmental impact is, besides efficiency, one of the main objectives.
F. For success it is a great need of international cooperation.

G. Should be considered the globalized trade consequences (all of them!).

H. Extension activities are important vectors for knowledge spreading.

I. Implementation of agriculture 4.0 is a long-term work.

J. The faster success of agriculture 4.0 needs a governmental support scheme.

K. Avoiding (as much as possible) the Dunning-Kruger effect is necessary.

\section{References}

1. United Nations Department of Economic and Social Affairs. World Population Projection, New York, United States. 
2. Pretty J (2008) Sustainability in Agriculture: Recent progress and Emergent challenges. Environmental Science and Technology Vol. 21.

3. http://www.fao.org/food-loss-and-food-waste/en/

4. Hamelinck C (2013) Biofuels and food security - Risks and opportunities. Ecofys, Utrecht, Netherlands.
5. Naghiu Al (2014) Apparatus and systems for measurement in environment engineering, Risoprint, Cluj-Napoca, Romania.

6. https://www.rothamsted.ac.uk/future-agri-food-systems

7. Naghiu AL (2019) Considerazioni sulla Viticoltura 4.0. Annali Academia Nazionale di Agricoltura CXXXIX, Bologna, Italy, pp. 264-290.

For possible submissions Click below: 